\title{
Latent Class Analysis of Dental Treatment: Observed in IIUM Dental Specialist Clinic, Kuantan, Pahang
}

\author{
Azrul Fazwan Kharuddin ${ }^{1}$, Khadilla Ismail ${ }^{2}$, Siti Sarah Ghazali@Suhaimi ${ }^{2}$, Noraini Abu Bakar ${ }^{3}$ and Khairani Idah \\ Mokhtar ${ }^{4}$ \\ ${ }^{1}$ Department of Computational and Theoretical Sciences, Kulliyyah of Science, International Islamic \\ Universi ty Malaysia, Kuantan. \\ ${ }^{2}$ Kulliyyah of Dentistry, International Islamic University Malaysia,Kuantan. \\ ${ }^{3}$ Unit of Orthodontics, Kulliyyah of Dentistry, International Islamic University Malaysia,Kuantan. \\ ${ }^{4}$ Unit of Oral Biology, Kulliyyah of Dentistry, International Islamic University Malaysia,Kuantan.
}

\begin{abstract}
Research into dental treatment via statistical perspective was unraveled through a relation between theoretical and experimental probability. This assessment of association was examined using statistical test over Confirmatory Factor Analysis (CFA) and Latent Class Analysis (LCA). Theoretical results of the prevailing difference between the direct and indirect upshot was verified through a technique known as integrated model by using Mplus $®$ software package. The results expressively show that the dental treatment from the indirect effect has better performance than the direct effect. Besides that, there is a dramatic improvement of dental treatment from different type of malocclusion analysis. Three classes of different type of malocclusion analysis play an important role as mediator for demographic variable and type of dental treatment.
\end{abstract}

KEYWORDS: Latent class analysis, Malocclusion analysis, Dental treatment

\section{INTRODUCTION}

The latent class analysis is a method of analyzing statistical data with unobserved variables in health care. It has been used since the 1930 s to study collaboration in the process of classification and discrete measurement error. ${ }^{1}$ Modeling this latent class identifies the pattern of agreement or dispute among inspectors if strong assumptions about important discrete processes in estimating the frequency of "compromise". ${ }^{2}$ An important theory in standards will serve as a latent factor. Loglinear uniformity in latent class models can be seen through discrete data maintained as imperfect models.

Handling of simplicity and argument is used in a classification system which is a mix of analogous clinical case appearance. It is not a diagnostic system, but it is intended for an influential prognostic process or the way it is treated. In this particular orthodontic study, the classification of malocclusion plays some very important roles. Through the help

Corresponding author:

Azrul Fazwan bin Kharuddin

Department of Computational and Theoretical

Sciences ,

Kulliyyah of Science,

International Islamic University Malaysia,

Jalan Sultan Ahmad shah,

25200 Kuantan,

Pahang, Malaysia

Email: azrulfazwan@iium.edu.my of classification in diagnosis, malocclusions treatment planning can instruct clinicians on the type and magnitude of the problems and possible mechanical solutions to these problems. ${ }^{3}$ Occlusion can be defined as maxillary and mandibular dental contact when the jaw is closed with relative centrifugation and without muscle strain or condensation shift in their fossae.

Structured regression models can be interpreted to some criteria. The whole interpretation of the "dental treatment model" hypothesis to the latest study data is constructed through several suitable index models. ${ }^{4}$ Among them are chi-square, chisquare norm, CFI, SRMR, and RMSEA. In addition, parameter estimation is directly examined to interpret the effects of endogenous variables from other variables. In addition, the patient's background effect is also taken into account ${ }^{5}$ to control the direct and indirect effects of dental treatment. ${ }^{6}$ Finally, an explanation of the built model is obtained through the coefficient of correlation examined to investigate the amount of variance in each latent variable.

\section{MATERIALS AND METHODS}

There are several reasons why this latent class analysis method is selected for quantitative survey data in this report. Understanding the relationship of demographic factors, treatment of malocclusion and dentistry clarifies the questions put forth in this report. There is great value in using these resources since there is a primary data set in the science 
stream field. Hypothesis testing for structured regression models requires two-step law. Measurement model must be acknowledged first and then structure model must be identified. First, the confirmatory factor analysis model (CFA) should be checked for testing the measurement model. In the second step, the model and structural parts should be tested. This integrated statistical model confirms the exploration of research questions and allows key data analyzers to control for various sources of variation in dental achievement. It is important to assess the relative influence of various sources of variation and demands made by detraditionalisation theorists about the decline of traditional structure equations.

In general, this study is to confirm the relationship between demographic factors, types of malocclusion and their dental treatment.

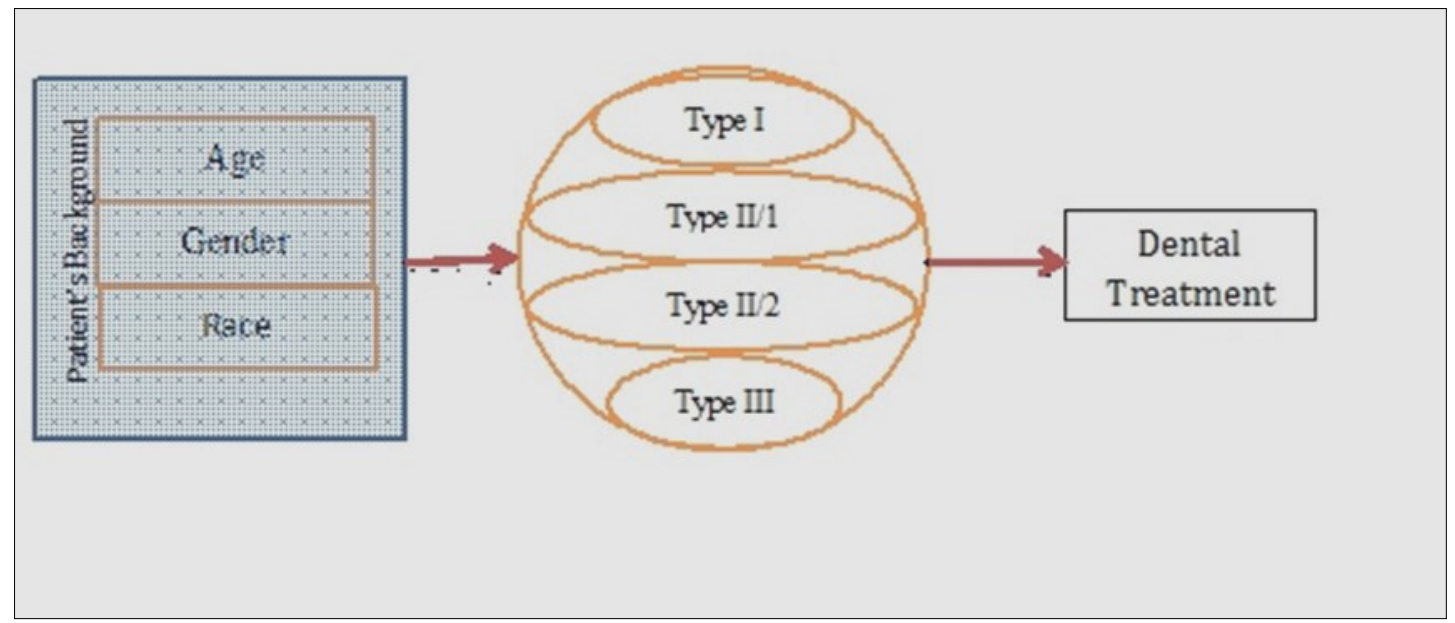

Figure 1: An integrated model of indications (patient's background), mediators (type of malocclusion) and outcome (dental treatment)

The analysis for age distribution, gender, race, teeth classification and type of treatment of the sample was presented using frequency (n) and percentage (\%). The findings in Table 1 showed that the majority of patients were women (403; $72.0 \%)$, while men only consist of $157(28.0 \%)$ of patients. The majority of patients receiving treatment were patients aged from 13 to 17 years old with $313(55.9 \%)$ and no representative of patients aged 0 to 6 years. About 508 (90.7\%) Malays received orthodontic treatment at the Dental Clinic of IIUM and whilst minority groups, Chinese $(5.7 \%)$, Indian and others consisting of $10(1.8 \%)$ patients per group.

Table 1: Demographic

\begin{tabular}{llll}
\hline Profiles & Categories & $\mathrm{n}=560$ & $\%$ \\
\hline Gender & Male & 157 & 28.0 \\
& Female & 403 & 72.0 \\
Age (years) & $0-6$ & 0 & 0 \\
& $7-12$ & 96 & 17.1 \\
& $13-17$ & 313 & 55.9 \\
& $\geq 18$ & 151 & 27.0 \\
Race & & \\
& Malay & 508 & 90.7 \\
& Chinese & 32 & 5.7 \\
& Indian & 10 & 1.8 \\
Others & 10 & 1.8
\end{tabular}

Percentages standardized to the nearest $0.1 \%$

The analysis also found that 191 (34.1\%) patients were classified as Class III maloclusion based on BSI incision classification and followed by Class II divisions 1 with a slight difference of $8(1.4 \%)$ of patients. The least the number of malocclusions found is Class II division 2 with 42 (7.5\%) patients. 
Table 2: Distribution of Sample by Types of Malocclusion (BSI Incisor Classification), $n=560$

\begin{tabular}{lcc}
\hline Incisor classification & $\mathrm{n}$ & $\%$ \\
\hline Class 1 & 144 & $25.7 \%$ \\
Class II div 1 & 183 & $32.75 \%$ \\
Class II div 2 & 42 & $7.5 \%$ \\
Class III & 191 & $34.1 \%$ \\
\hline
\end{tabular}

Percentages standardized to the nearest $0.1 \%$

Based on Figure 2, it shows that the highest type of treatment received by the patient is fixed appliance $(336 ; 60.0 \%)$ and followed by the combination of removable and fixed appliance (90; 16.1\%). The removable appliances treatment represented by $70(12.5 \%)$ cases and patients receiving consultation only were $46 \quad(8.2 \%)$. Combination of treatment with functional \& fixed appliance and cases treated with functional appliances alone were $12(2.1 \%)$ and 6 (1.1\%) respectively.

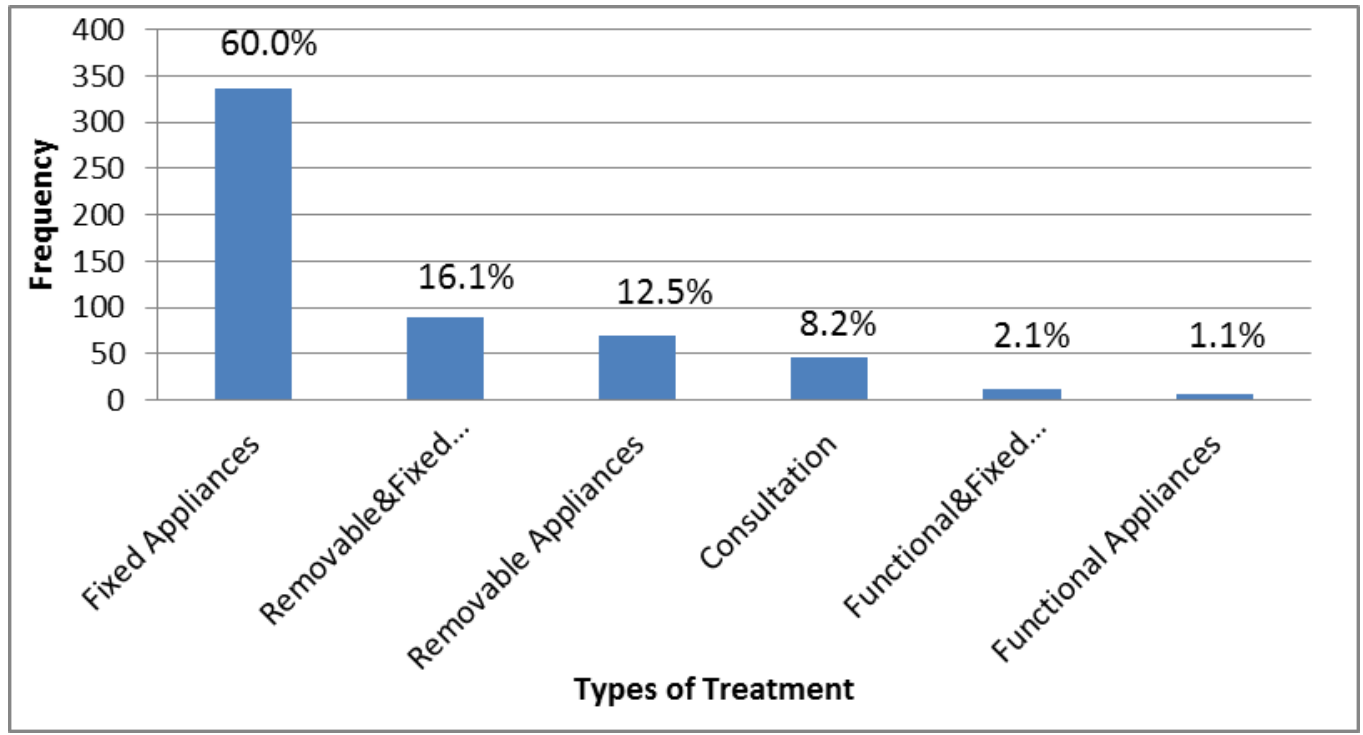

Figure 2: Distribution of Sample by Type of Treatments Received by Patients, $n=560$ Percentages standardized to the nearest $0.1 \%$

\section{STATISTICAL ANALYSIS}

The benefits of an integrated lined class model for this dental treatment show that multiple correlations between variables can be summarized in the model by expressing relative effects with some independent variables. These models estimate the remaining impression of the remaining variables (ceteris paribus). ${ }^{7.8}$ Demand for such modeling requires a lot of explanation. Firstly, considering the difference between patient demographics with controlling the relevant variables. Secondly, the type of malocclusion that is owned to assess their relative contribution to dental treatment in the model. Then, the interaction effect between the variables can be explored to see if the effects are consistent or whether they have the influence interfere by the other factors. Finally, monitoring changes over time and striving to improve existing modeling procedures. This is where the explanatory factor analysis predicts other variables, such as age and gender. The effect of multiple variables does not use mediating variables and results in well-recognized interpretation problems. ${ }^{8}$

From multivariate regression analysis result in Table 3 showed that:

Model $\mathrm{H}_{\mathrm{a}}$ : Interestingly, there was indirect effect for relationship of age and gender towards types of treatment mediated by the types of malocclusion. 
Table 3: Regression analysis

\begin{tabular}{ccc}
\hline Model $H_{4}$ & $\mathrm{Y}_{1}$ & $\mathrm{p}=0.006$ \\
& $\mathrm{Y}_{2}$ & $\mathrm{p}=0.009$ \\
\hline \multicolumn{3}{c}{ Coefficients } \\
\hline Variables & Significant value \\
\hline & Age & 0.009 \\
$\mathrm{Y}_{2}$ & Gender & 0.092 \\
& Age & 0.013 \\
& Gender & 0.101 \\
& Types of malocclusion & 0.233 \\
\end{tabular}

* Significant at $p<0.05$

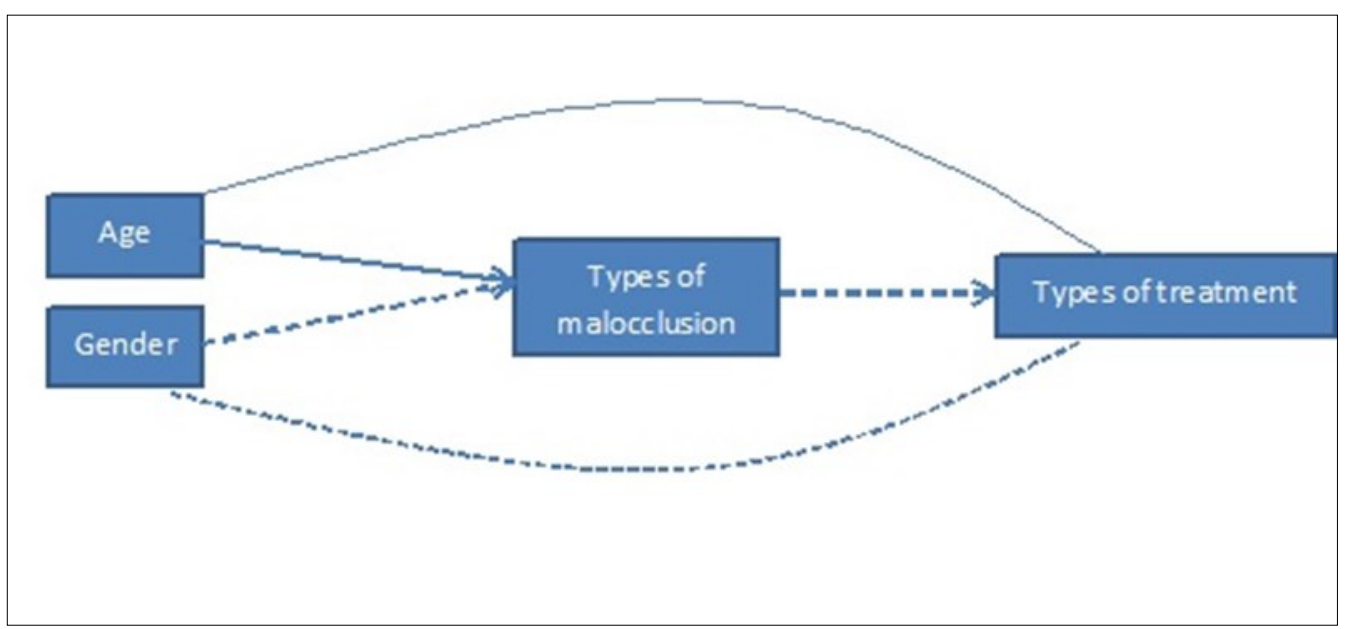

Figure 3: Model $\mathrm{H}_{\mathrm{a}}$ framework:

Figure 3 generally indicates that this study is to confirm the latent class categories of the type of treatment among malocclusion patients and their dentistry. Based on the conceptual framework (Figure 4), they consist of Class I - normal category $(\mathrm{C} 1 \mathrm{~N})$, Class II Division 1 - increased overjet (C2D1PO), Class II Part II - retroclined upper incisors (C2D2RO), and class III - reverse overjet (C3U). Age and sex seems to play an important role in determining the treatment class received by the patient.

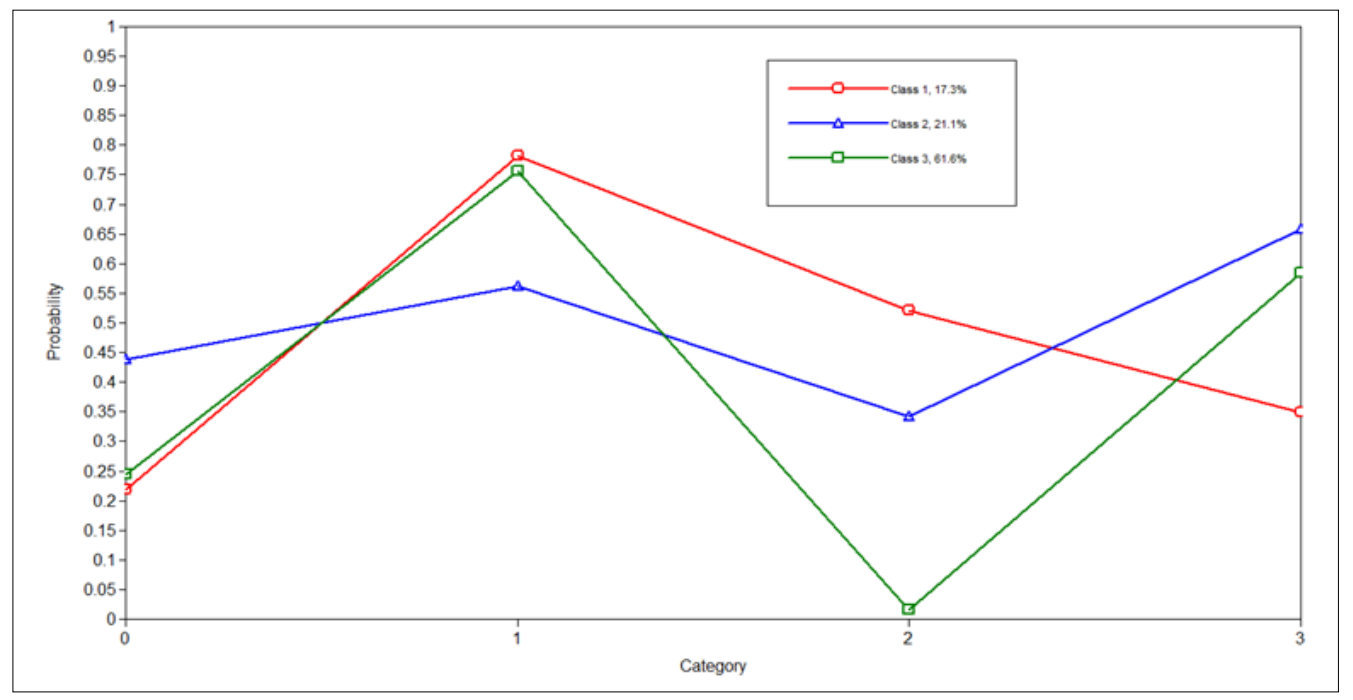

Figure 4: Malocclusion Item Probabilities of Orthodontic Treatment on Three Performances 


\section{DISCUSSION}

Five items from the variable of orthodontics patients were used to estimate the latent class model value. The significant value $(p<0.05)$ against the Log-likelihood ratio chi square (LL) was tested. There was significant difference between classes to allow formation of the 3 latent classes. Besides that, the steadiness of likelihood ratio through the Lo-Mendell-Rubin Likelihood Ratio Test (LMRLRT) process also supports the choice of these 3 categories. Moreover, this test also improves the minimum value for Bayesian Information Criterion (BIC) and Akaike Information Criterion (AIC) besides stable value of adjusted $\mathrm{BIC}(\mathrm{aBIC})$ to segregate type of malocclusions treatment of orthodontics patients. ${ }^{10}$

The class I shaped from 3 latent classes which categorized as having normal category. Least respondents given by $97(17.28 \%)^{11}$ patients from this category were encouraging normal Class I malocclusion type $(\mathrm{C} 1 \mathrm{~N})$ and received removable appliances treatment. The Class II represented by $118(21.10 \%)$ patients with increased overjet. ${ }^{12}$ This Class II category was further divided into two divisions namely Class II Division I - proclined upper incisors (C2D1PUI) and Class II Division II retroclined upper incisors (C2D2RUI). Proclined upper incisors patients received combine functional and fixed appliances treatment, whereas retroclined upper incisors were treated with combine removable and fixed appliances. The remaining $345(61.62 \%)^{13}$ patients were categorized as reverse overjet (Class III) and mostly treated with fixed appliances treatment. ${ }^{14}$ These can be expressed in Figure 3 describing type of treatment received by malocclusion patients according to the resulting latent class.

\section{CONCLUSION}

In summary, our study reveals that the majority of patients in the IIUM Orthodontic Clinic are Class III and we categorize them as reverse overjet patients. They received fixed appliances treatment. Patients between the ages of 13 and 17 are the major groups with the highest frequency. The result also shows that the Malays are the dominant race and fixed appliances were the most popular choice of treatment. Interestingly, the analysis obtained from this study concludes that age and gender have a significant effect on the type of treatment completed by the type of malocclusion. The data obtained will be useful for literature, future dental management and clinical planning.

\section{ACKNOWLEDGEMENT}

The authors would like to acknowledge the financial support and staff of the Orthodontic Department, Kulliyyah of Dentistry, IIUM for their assistance during this study through the IIUM Research Initiative Grant Scheme (IIUM-RIGS -15-
045- 0045)

\section{REFERENCES}

1. Lewin, Kurt, and T. Dembo. "Untersuchungen zur Handlungs-und Affektpsychologie. X. Der Arger als dynamisches Problem." Psychologische Forschung. 1931; 15: 1-44

2. Martin, C. R., Lewin, R. J., \& Thompson, D. R. (2003). A confirmatory factor analysis of the Hospital Anxiety and Depression Scale in coronary care patients following acute myocardial infarction. Psychiatry research. 2003; 120: 85-94.

3. Nishio, C. \& Mucha, J. N. Agreement Evaluation of a Newly Proposed System for Malocclusion Classification Miguel-neto, A. B. Int. J. Odontostomat 2010; 4:33-41

4. Muthén, L. K., \& Muthén, B. O. Mplus user's guide. 7th ed. Los Angeles: Muthén \& Muthén. 2012.

5. Pascarella, E. T., Whitt, E. J., Nora, A., \& Edison, $M$. What have we learned from the first year of the national study of student learning? Journal of College Student Development. 1996; 37: 182-92

6. White, P., \& Mitchelmore, M. Conceptual knowledge in introductory calculus. Journal for Research in Mathematics Education 1996; Jan: 79-95.

7. Dale, A., \& Davies, R. B. (Eds.). Analyzing social and political change: a casebook of methods. Sage. 1994.

8. Ganzeboom, H. B., \& Treiman, D. J. International stratification and mobility file: Conversion tools. Accessed June, 22, 2009.

9. Asher, S. R., \& Oden, S. L. Children's failure to communicate: An assessment of comparison and egocentrism explanations. Developmental Psychology 1976; 12:132.

10. Bruin, A. Towards Advancing Understanding of Social Innovation. In Challenge Social Innovation (pp. 367-377). Springer Berlin Heidelberg. 2012.

11. Fuller, J. K. Maxillary central incisor crownroot relationships in class I normal occlusions and class III open and deep malocclusions. The University of lowa. 2015.

12. Martina, R., Uomo, R., Baldares, S., Galeotti, A., \& D'Antò, V. The Use of the Sander BiteJumping Appliance in the Correction of Class II Division 1 Malocclusion in Hypodivergent Patients with a Deep Overbite. European Journal of Clinical Orthodontics 2016; 4: 1622.

13. Roberts, W. E., Viecilli, R. F., Chang, C., Katona, T. R., \& Paydar, N. H. (2015). Biology of biomechanics: Finite element analysis of a statically determinate system to rotate the occlusal plane for correction of a skeletal Class III open-bite malocclusion. American Journal of Orthodontics and Dentofacial Orthopedics 2015; 148: 943-955. 
14. Kaaij, N. C., Veen, M. H., Kaaij, M. A., \& Cate, J. M. A prospective, randomized placebo -controlled clinical trial on the effects of a fluoride rinse on white spot lesion development and bleeding in orthodontic patients. European journal of oral sciences 2015; 123:186-193. 